Crustaceana

\title{
A NEW SPECIES OF SQUAT LOBSTER OF THE GENUS MUNIDA (GALATHEOIDEA, MUNIDIDAE) FROM THE RED SEA

\author{
--Manuscript Draft--
}

\begin{tabular}{|c|c|}
\hline Manuscript Number: & \\
\hline Full Title: & $\begin{array}{l}\text { A NEW SPECIES OF SQUAT LOBSTER OF THE GENUS MUNIDA } \\
\text { (GALATHEOIDEA, MUNIDIDAE) FROM THE RED SEA }\end{array}$ \\
\hline Short Title: & Munida from Red Sea \\
\hline Article Type: & Special Issue: Volume in Honour of Michael Türkay \\
\hline Keywords: & Anomura, taxonomy, deep-water coral, new species, Munida \\
\hline Corresponding Author: & $\begin{array}{l}\text { Enrique MacPherson } \\
\text { Cetro de Estudios Avanzados de Blanes (CSIC) } \\
\text { Blanes, Girona SPAIN }\end{array}$ \\
\hline Corresponding Author's Institution: & Cetro de Estudios Avanzados de Blanes (CSIC) \\
\hline First Author: & Enrique MacPherson \\
\hline Order of Authors: & Enrique MacPherson \\
\hline Manuscript Region of Origin: & SAUDI ARABIA \\
\hline Abstract: & $\begin{array}{l}\text { During a deep-water expedition to the Red Sea a rare squat lobster of the genus } \\
\text { Munida was collected. The species is considered a new species characterized by the } \\
\text { presence of a pterygostomian flap visible from the dorsal side and with spines in the } \\
\text { flap at level of the branquial region. The new species, Munida turkayi, is related to M. } \\
\text { bapensis, from the Gulf of Mexico, } 620 \mathrm{~m} \text {, and M. macrobrachia, from Southern } \\
\text { California, } 540-612 \mathrm{~m} \text {. M. turkayi is easily distinguished from these two species by } \\
\text { numerous characters. For instance, the dorsal surface of the gastric region has } \\
\text { numerous spines in M. turkayi, whereas these spines are less numerous in the other } \\
\text { two species. Furthermore, there are } 3 \text { distinct carinae on the lateral portion of the } \\
\text { sternite } 7 \text { in the new species, whereas these lateral portions are smooth (M. } \\
\text { macrobrachia) or with numerous granules (M. bapensis). }\end{array}$ \\
\hline Suggested Reviewers: & $\begin{array}{l}\text { Tomo Komai } \\
\text { komai@chiba-muse.or.jp } \\
\text { expert in the group }\end{array}$ \\
\hline & $\begin{array}{l}\text { Keiji Baba } \\
\text { kbaba.kumamoto@gmail.com } \\
\text { expert in the group }\end{array}$ \\
\hline Opposed Reviewers: & \\
\hline Funding Information: & \\
\hline
\end{tabular}




\title{
A NEW SPECIES OF SQUAT LOBSTER OF THE GENUS MUNIDA (GALATHEOIDEA, MUNIDIDAE) FROM THE RED SEA
}

\author{
BY \\ E. MACPHERSON ${ }^{1,5}$, L. BEUCK ${ }^{2}$, C. RODER ${ }^{3}$ and C.R. VOOLSTRA ${ }^{4}$ \\ ${ }^{1}$ Centro de Estudios Avanzados de Blanes (CEAB-CSIC) C. acc. Cala San Fracesc 14, 17300 \\ Blanes, Girona, Spain. E-mail: macpherson@ceab.csic.es (EM) \\ ${ }^{2}$ Senckenberg am Meer, Marine Research Department, Südstrand 40, D-26382 Wilhelmshaven, \\ Germany.E-mail: Lydia.Beuck@senckenberg.de (LB) \\ ${ }^{3}$ Alfred-Wegener Institut Helmholtz-Zentrum für Polar- und Meeresforschung, am Binnenhafen \\ 1117, D-27498 Helgoland, Germany (CR \\ ${ }^{4}$ Red Sea Research Center, King Abdullah University of Science and Technology, Thuwal, Saudi \\ Arabia (CV) \\ ${ }^{5}$ corresponding author
}

\begin{abstract}
During a deep-water expedition to the Red Sea a rare squat lobster of the genus Munida was collected. The species is considered a new species characterized by the presence of a pterygostomian flap visible from the dorsal side and with spines in the flap at level of the branquial region. The new species, Munida turkayi, is related to M. bapensis, from the Gulf of Mexico, $620 \mathrm{~m}$, and $M$. macrobrachia, from Southern California, 540-612 m. M. turkayi is easily distinguished from these two species by numerous characters. For instance, the dorsal surface of the gastric region has numerous spines in $M$. turkayi, whereas these spines are less numerous in the other two species. Furthermore, there are 3 distinct carinae on the lateral portion of the sternite 7 in the new species, whereas these lateral portions are smooth ( $M$. macrobrachia) or with numerous granules (M. bapensis). M. turkayi was caught in the central Red Sea off Thuwal (Saudi Arabia) in $320 \mathrm{~m}$ depth. Here, this species co-occurs with live colonies of Eguchipsammia fistula (Alcock, 1902), which occur patchy and partly buried on soft sediment in warm, oxygen- and nutrient-limited water masses.
\end{abstract}

Keywords

Anomura, taxonomy, deep-water coral, new species, Munida 


\section{INTRODUCTION}

The Red Sea is considered one of the "hot spots" in marine biodiversity of the world, and numerous authors have studied the crustacean decapods of the area demonstrating the existence of a very rich fauna, with a high proportion of endemic species (Spiridonov \& Apel 2007; Werding \& Hiller 2007; DiBattista et al. 2016). Among these decapods, the squat lobsters (Chirostyloidea and Galatheoidea) are considered one of the most diverse groups (Baba et al. 2008; Macpherson \& Robainas-Barcia 2015).

The genus Munida Leach, 1820, is one of the most diverse taxa of squat lobsters of the family Munididae Ahyong et al. 2010, and is represented in the Red Sea by 5 species (Baba et al. 2008; Macpherson \& Baba 2011; Macpherson et al. 2016): M. babai Tirmizi \& Javed, 1976, M. dispar Macpherson \& Baba, 1993, M. eudora Macpherson \& Baba, 1993, M. janetae Tirmizi \& Javed, 1992, M. roshanei Tirmizi, 1966. During a cruise to the Red Sea (Saudi Arabia) in May 2013, a new species of Munida was collected from bathyal depths of the central Red Sea associated with deep-sea corals (Fig. 1). In the present study we describe and illustrate this new species and characterise its environment.

\section{MATERIAL AND METHODS}

The sample was collected during the Leg 6 of the KAUST Red Sea Expedition (KRSE) 2013 off Thuwal, Saudi Arabia (Red Sea) on board the RV Aegaeo. The expedition aimed to investigate deep-sea coral habitats in the central and northern Saudi Arabian Red Sea. The sampling occurred via a scoop used by a manipulator arm of the remotely operated vehicle (ROV) 'Max Rover'. The live organisms were stored in seawater $\left(+21^{\circ} \mathrm{C}\right)$ for subsequent macroscopic and microscopic documentation, prior fixation in ethanol ( $\geq 96 \%$ with $1 \% \mathrm{MEK}$ Ethylalcohol). Via timecode, the video material was linked to the ROV navigation track.

Environmental conditions in $320 \mathrm{~m}$ depth derive from four CTD downcasts (stations KRSE2013-6-4-2/1, KRSE2013-6-4-2/9, KRSE2013-6-4-2/15, KRSE2013-6-4-2/16), carried out in that working area off Thuwal.

The material is deposited at the Senckenberg Research Institute and Natural History Museum, Frankfurt am Main (SMF) (see collection database SeSam: 
http://sesam.senckenberg.de). The measurements given are the carapace length, excluding rostrum. The terminology used follows Baba et al. (2009). The size of the specimen is indicated by the postorbital carapace length. Measurements of appendages are taken in dorsal (pereopod 1), lateral (antennule, pereopods 2-4) and ventral (antenna) midlines. Ranges of morphological and meristic variations are included in the description. Abbreviations used are: $\mathrm{G}=$ gonopod; $\mathrm{Mxp} 3=$ maxilliped 3; P1, pereiopod 1; P2-4, pereopods 2-4.

\section{SYSTEMATIC ACCOUNT}

Munida turkayi n. sp.

(Figs. 2, 3)

HOLOTYPE. - Off Thuwal (Red Sea), RV Aegaeo, sta. KRSE 2013-6-4-1/4d-, ROV dive no. 6, 22 ${ }^{\circ} 17.826^{\prime} \mathrm{N}, 38^{\circ} 53.808^{\prime} \mathrm{E}, 10$ May 2013, $320 \mathrm{~m}$ : Male $7.3 \mathrm{~mm}$ (SMFxxxx).

Etymology. Named for our friend and colleague, Michael Türkay, for his important contributions to carcinology.

\section{DESCRIPTION}

Carapace: 1.3 times longer than broad, dorsal ridges with dense short noniridescent setae and few scattered long iridescent and non-plumose setae. Gastric region with two transverse rows of epigastric spines, each with 4 pairs of spines, and one longitudinal row with 3 unpaired median spines behind rostral spine; protogastric region with 3 pairs of small spines. Two branchial dorsal spines and 3 postcervical spines on each side. Frontal margins transverse. Orbit visible in dorsal view, wih spinose crest ventrally and 2 small spines on dorsal side. Lateral margins straight. First lateral spine at anterolateral angle, long, clearly not reaching level of sinus between rostrum and supraocular spines; one small spine in front of anterior branch of cervical groove. Branchial margins with 3 spines. Rostrum spiniform, about 0.6 times length of remaining carapace, horizontal, dorsally not carinated. Supraocular spines barely reaching midlength of rostrum 
and not reaching end of corneae, subparallel and slightly upwards directed. Pterygostomian flap dorsally visible, with 4 spines.

Sternum: Distinct 3 carinae on lateral portion of sternite 7. Few short striae on sternite 4; distal margin of sternite 4 narrow, not contiguous to sternite 3.

Abdomen: Anterior ridge of somite 2 unarmed; somites 2-4 each with one transverse ridges on tergite behind anterior ridge; posteromedian margin of somite 6 straight. $\mathrm{G} 1$ and $\mathrm{G} 2$ present.

Eyes: Ocular peduncles as long as broad, maximum corneal diameter 0.4 distance between bases of anterolateral spines.

Antennule: Article 1 (distal spines excluded) about 0.7 carapace length, elongate, 3 times longer than wide (excluding spines), clearly overreaching end of corneae, with 2 subequal distal spines, 2 spines on lateral margin, proximal one short, located at mid length of article, distal one long, not reaching end of segment (excluding spines); distance between distal end of segment and base of dorsolateral spine 0.8 length of remaining proximal portion.

Antenna: Article 1 with strong distomesial spine reaching distal margin of article 2. Article 2 with distomesial spine not reaching end of antennal peduncle; distolateral spine reaching midlength of article 3 . Article 3 with distomesial spine exceeding peduncle. Article 4 with small distolateral spine.

Mxp3: Ischium with distal spine on flexor and extensor margin; crista dentate with 26 denticles. Merus shorter than ischium; flexor margin with 3 spines, proximal spine stronger than others; extensor margin with distal spine. Carpus unarmed.

$P 1: 3.0$ times carapace length, with some long iridescent and plumose setae along mesial margins of articles. Merus 1.1 length of carapace, 1.5 times as long as carpus, with some dorsal spines; distal spines strong, distomesial spine not reaching proximal third of carpus. Carpus as long as palm, 2.7 times as long as broad, with spines along mesial and dorsal sides. Palm 2.1 times longer than broad, with some small dorsal spines; few spines along lateral margin continuing along lateral margin of fixed finger; mesial row of spines continuing along proximal half of movable finger. Fingers as long as palm.

P2-3 (P4 missing): Moderately long and slender, with numerous plumose and iridiscent setae along extensor margin of articles. P2 2.4 times carapace length. Meri shorter posteriorly (P3 merus 0.8 length of P2 merus); P2 merus 0.9 length of 
carapace, 7.5 times as long as broad, 1.3 times longer than $\mathrm{P} 2$ propodus; $\mathrm{P} 3$ merus 6 times longer than broad, as long as P3 propodus. Extensor margins of P2-3 meri with row of 7-10 proximally diminishing spines; flexor margins distally with some spines followed proximally by several eminences. Carpi with 4 spines on extensor margin of P2-4; lateral surface with several granules sub-paralleling extensor margin on P2-3; flexor margin with distal spine. Propodi 8.6-9.0 times as long as broad; extensor margin unarmed; flexor margin with 7-8 slender movable spines. Dactyli slender, length 0.5 that of propodi; flexor margin with 8-9 movable spinules, distal third unarmed.

Colour: Ground colour of carapace, abdomen whitish, spines, striae and ridges reddish. Rostral and supraocular spines whitish, with lateral margins reddish. Sternite 3, and distal portion of sternite 4 reddish. P1-4 whitish with red stripes; P1 fingers with proximal and distal parts whitish; P2-3 dactyli whitish.

\section{DISTRIBUTION.}

Off Thuwal (Red Sea) at $320 \mathrm{~m}$, associated with live colonies of Eguchipsammia fistula (Alcock, 1902), which occur patchy and partly buried on soft sediment (Fig. 4). M. turkayi is known to dwell in warm temperatures of $21.6^{\circ} \mathrm{C}$, salinity of $40.5 \mathrm{PSU}$, at a pH value of 8.3 , oxygen values of $8.4 \%$ and under highly oligothrophic conditions (see also Roder et al. 2013 and Rooik et al. 2015).

\section{REMARKS}

Munida turkayi belongs to the group of species with the pterygostomian flap visible from the dorsal side. This character is also shared with the genus Pleuroncodes and contains few species, all of them from the Eastern Pacific. Furthermore, the new species is the unique species of the genus with spines in the pterygostomian flap at level of branquial region.

The new species is related to $M$. bapensis Hendrickx, 2000, from the Gulf of Mexico, 620 m, and M. macrobrachia Hendrickx, 2003, from Southern California, 540-612 m. Munida turkayi is easily distinguished from these two species by several characters:

- The dorsal surface of the gastric region has numerous spines in M. turkayi, whereas these spines are less numerous in the other two species. 
- The pterygostomian flap has some spines on the surface, next to branchial region, in $M$. turkayi, whereas the surface is unarmed in the other species (although M. macrobrachia has some spines in the anterior part of the flap).

- The abdominal somites are unarmed in the new species, whereas the somites 2-4 have some spines in the anterior ridge in $M$. bapensis.

- There are 3 distinct carinae on the lateral portion of the sternite 7 in the new species, whereas these lateral portions are smooth (M. macrobrachia) or with numerous granules ( $M$. bapensis).

- The antennular article 1 has two subequal distal spines in the new species, whereas these spines are clearly different in size in $M$. bapensis and $M$. macrobrachia. Furthermore, the article 1 is clearly more elongate in $M$. turkayi than in the other two species.

- The antennal article 3 has one strong distomesial spine in M. turkayi, whereas this spine is absent in the other two species.

\section{ACKNOWLEDGEMENTS}

We thank our colleague Michael Türkay for placing at our disposal this interesting specimen and for his friendship, support, fruitful discussions and efforts in the improvement of the crustacean collections. We also express our sincere thanks to the captain, his crew and the shipboard staff of KRSE 2013 Leg 6 on RV Aegaeo. We thank Frank Mallon for the CTD casts. Jürgen Titschack (JT) is thanked for his support in documenting sampled live organisms and processing multibeam data. LB received funds from EU-FP7 Projects CoralFISH (contract no. 213144), HERMIONE (contract no. 226354) and the Hessian initiative for the development of scientific and economic excellence (LOEWE) at the Biodiversity and Climate Research Centre (BiK-F), Frankfurt, Germany.

\section{REFERENCES}

AHYONG, S.T., K. BABA, E. MACPHERSON \& G.C.B. POORE, 2010. A new classification of the Galatheoidea (Crustacea: Decapoda: Anomura). Zootaxa, 2676: 57-68. 
BABA, K., E. MACPHERSON, G.C.B. POORE, S.T. AHYONG, A. BERMUDEZ, P. CABEZAS, C.W. LIN, M. NIZINSKI, C. RODRIGUES \& K. E. SCHNABEL, 2008. Catalogue of squat lobsters of the world (Crustacea: Decapoda: Anomura - families Chirostylidae, Galatheidae and Kiwaidae). Zootaxa, 1905: 1-220.

BABA, K., E. MACPHERSON, C.W. LIN \& T.Y. CHAN, 2009. Crustacean Fauna of Taiwan. Squat lobsters (Chirostylidae and Galatheidae). National Taiwan Ocean University, Keelung.

DIBATTISTA, J.D., J.H. CHOAT, M.R. GAITHER, J.P.A HOBBS, D.F. LOZANOCORTES, R.F. MYERS, G. PAULAY, L.A. ROCHA, R.J. TOONEN, M.W. WESTNEAT \& M.L. BERUMEN, 2016. On the origin of endemic species in the Red Sea. Journal of Biogeography, 43: 13-30.

HENDRICKX, M.E., 2000. The genus Munida Leach (Crustacea, Decapoda, Galatheidae) in the eastern tropical Pacific, with description of two new species. Bull. I'Inst. Roy. Sci. Nat. Bel., 70: 163-192.

HENDRICKX, M.E., 2003. The temperate species of the genus Munida Leach (Crustacea, Decapoda, Galatheidae) in the east Pacific, with the description of a new species and additional records for tropical-subtropical species. Bull. I'Inst. Roy. Sci. Nat. Bel., 73: 115-136.

MACPHERSON, E. \& K. BABA, 1993. Crustacea Decapoda: Munida japonica Stimpson, 1858, and related species (Galatheidae). In: A. CROSNIER (ed.), Résultats des Campagnes MUSORSTOM, volume 10. Mém. MuS. Nat. d'Hist. Nat., Paris, 156: 381-420.

MACPHERSON, E. \& K. BABA, 2011. Chapter 2. Taxonomy of squat lobsters. In: G.C.B POORE, S.T. AHYONG \& J. TAYLOR (eds), The biology of squat lobsters: 39-71. (CSIRO Publishing: Melbourne and CRC Press: Boca Raton). MACPHERSON, E. \& A. ROBAINAS-BARCIA, 2015. Species of the genus Galathea Fabricius, 1793 (Crustacea, Decapoda, Galatheidae) from the Indian and Pacific Oceans, with descriptions of 92 species. Zootaxa, 3913: 1-335.

MACPHERSON, E., P. RODRIGUEZ-FLORES \& A. MACHORDOM, 2016. Use of morphological and molecular data to identify new sibling species and new occurrences of squat lobsters (Eumunididae, Munididae, Munidopsidae) from the western Indian Ocean. Eur. Journ. Tax. (submitted). 
RODER, C., M.L. BERUMEN, J. BOUWMEESTER, E. PAPATHANASSIOU, A. AL-SUWAILEM \& C.R. VOOLSTRA, 2013. First biological measurements of deep-sea corals from the Red Sea. Scient. Rep., 3: doi:10.1038/srep02802 ROIK, A., T. RÖTHIG, C. RODER, P.J. MÜLLER \& C.R. VOOLSTRA, 2015.

Captive rearing of the deep-sea coral Eguchipsammia fistula from the Red Sea demonstrates remarkable physiological plasticity. PeerJ, 3:e734

SPIRIDONOV, V.A. \& M. APEL, 2007. A new species and new records of deepwater Calappidae (Crustacea: Decapoda) from the Indian Ocean with a key to the Mursia Desmarest, 1823 species of the región. Journ. Nat. Hist., 41: 28512890.

TIRMIZI, N.M., 1966. Crustacea: Galatheidae. The John Murray Expedition 193334. Scient. Rep., 11: 167-234.

TIRMIZI, N.M. \& W. JAVED, 1976. A new species of Munida from the Indian

Ocean with a redescription of a syntype of Munida spinulifera Miers, 1884 (Decapoda, Galatheidea). Crustaceana, 31: 81-89.

TIRMIZI, N.M. \& W. JAVED, 1992. Two new species of Munida Leach, 1820

(Decapoda, Anomura, Galatheidae) from the Indian Ocean. Crustaceana, 62: 312-318.

WERDING, B. \& A. HILLER, 2007. The Porcellanidae (Crustacea: Decapoda: Anomura) of the Red Sea with description of a new species of Petrolisthes. Zootaxa, 1460: 1-24.

\section{CAPTIONS}

Fig. 1. Overview map of the Red Sea, showing the sampling site of Munida turkayi n. sp. in red $\left(22^{\circ} 17.826^{\prime} \mathrm{N}, 38^{\circ} 53.808^{\prime} \mathrm{E}, 320 \mathrm{~m}\right.$ water depth).

Fig. 2. Munida turkayi n. sp., holotype, male $7.3 \mathrm{~mm}$ (SMF), Red Sea. A. Carapace and abdomen, dorsal view. B. Sternal plastron. C. Cephalic region, showing antennular and antennal peduncles, ventral view. D. Anterior part of carapace, showing ocular peduncle and orbit, right, dorsal. E. Right pterygostomian flap, lateral view. Scale: A, E = $2.0 \mathrm{~mm} ; \mathrm{B}, \mathrm{C}, \mathrm{D}=1.0 \mathrm{~mm}$. 
Fig. 3. Munida turkayi n. sp., holotype, male $7.3 \mathrm{~mm}$ (SMF), Red Sea. A. Right Mxp3, lateral view. B. Right P1 merus and carpus, dorsal view. C. Right P1 palm and fingers, dorsal view. D. Right P2, lateral view. E. Dactylus of right P2, lateral view. F. Right P3, lateral view. Scale: A, E = $1.0 \mathrm{~mm} ; \mathrm{B}, \mathrm{C}, \mathrm{D}, \mathrm{F}=2 \mathrm{~mm}$.

Fig. 4. ROV images of sampling site (sta. KRSE2013-6-4-1/4d), 320 m water depth. Images by courtesy of HCMR, Greece. A. Overview image of biotope with live colonies of Eguchipsammia fistula (Alcock, 1902) occurring patchy and partly buried on soft sediment. B. Detailed image with live E. fistula colonies; note the scoop (sampling tool), used by the manipulator arm of the ROV. 


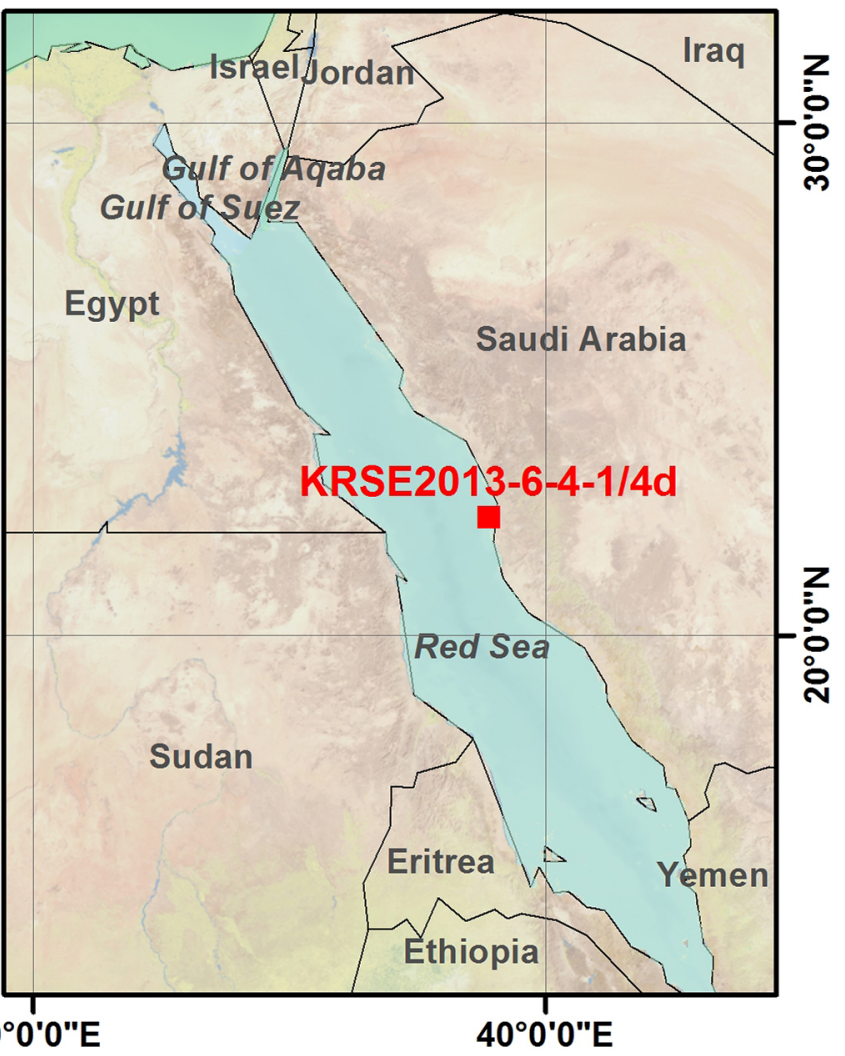




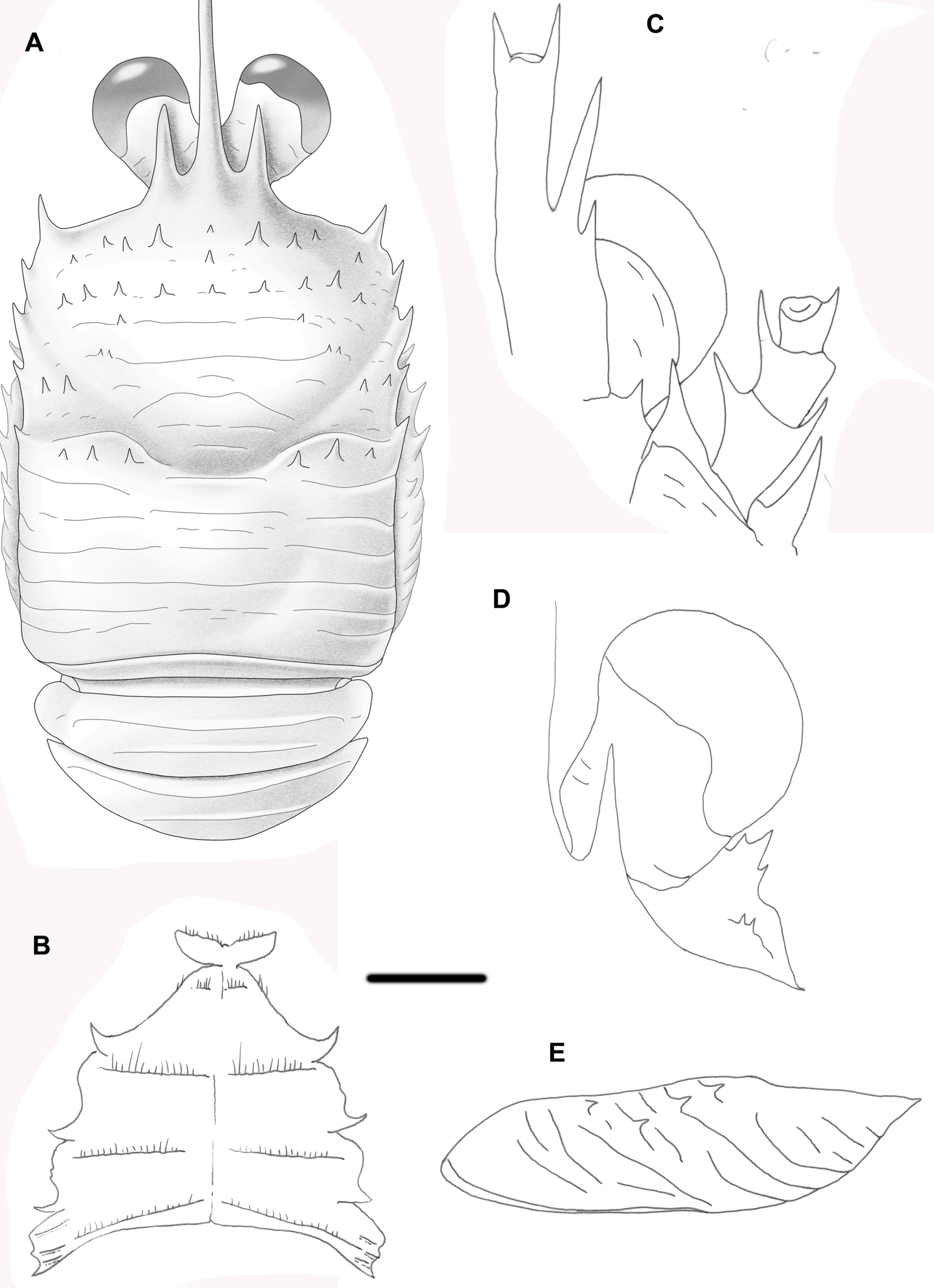




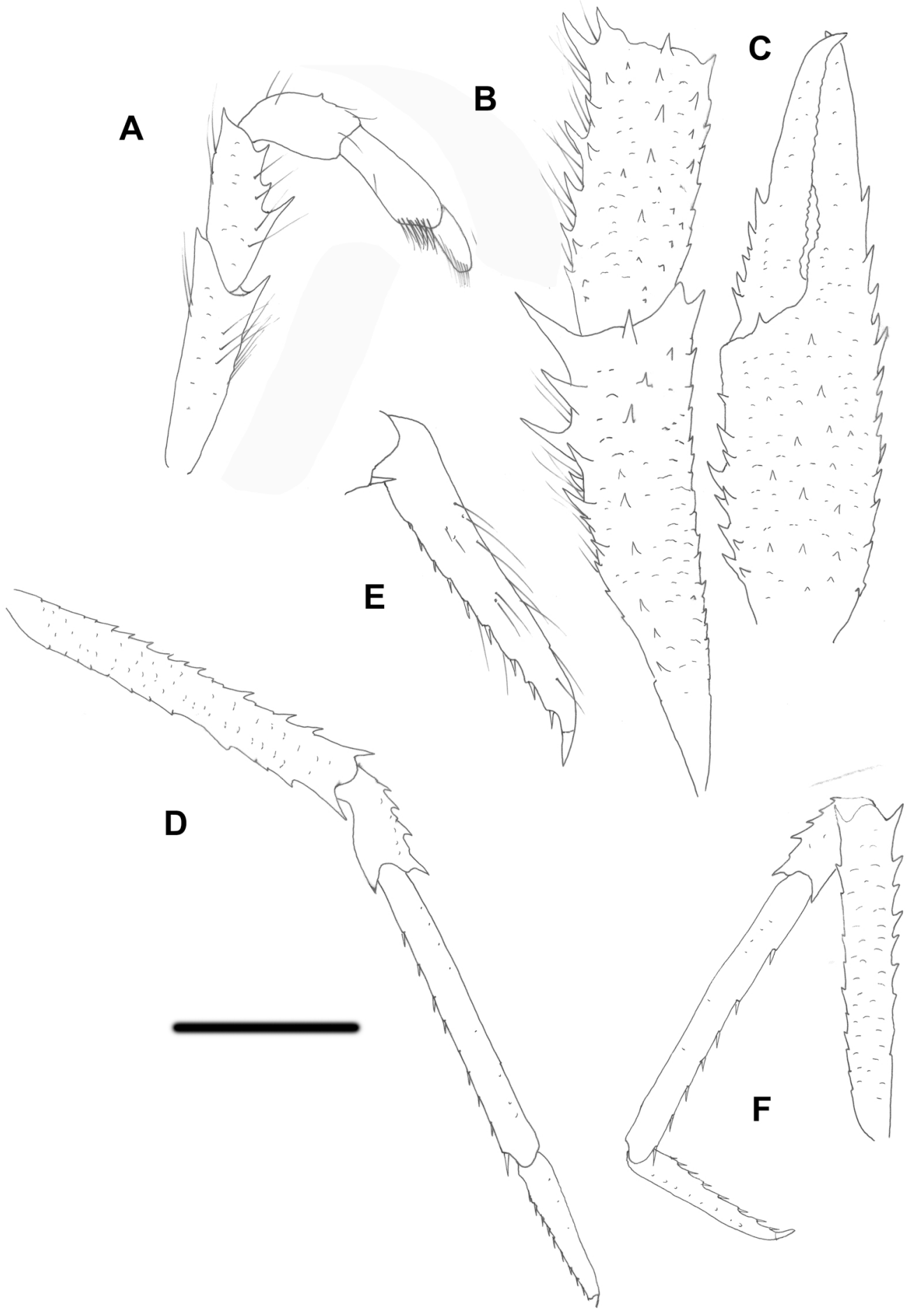


W.
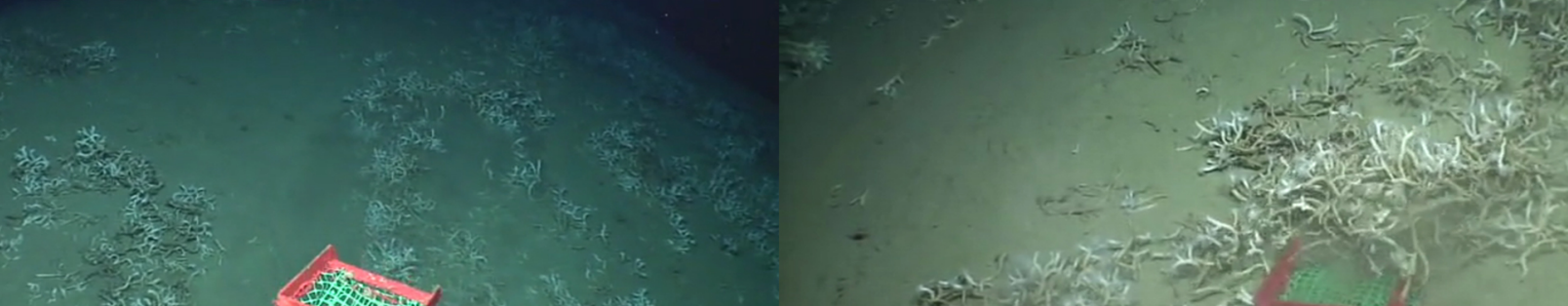